Universidad

:

BIBLIOTECA

Document downloaded from the institutional repository of the University of Alcala: http://ebuah.uah.es/dspace/

This is the peer reviewed version of the following article:

Vázquez, J.J., Panadero, S. \& Zúñiga, C. (2017). Content and uniformity of stereotypes and meta-stereotypes of homeless people in Madrid (Spain). Journal of Community Psychology, 45(1), 128-137. doi: 10.1002/jcop.21836, which has been published in final form at:

https://doi.org/10.1002/jcop.21836

This article may be used for non-commercial purposes in accordance with Wiley Terms and Conditions for Use of Self-Archived Versions.

(C) 2016, Wiley Periodicals, Inc.

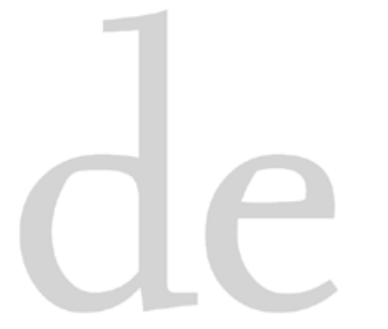

(Article begins on next page)

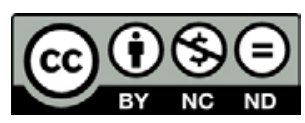

This work is licensed under a

Creative Commons Attribution-NonCommercial-NoDerivatives

4.0 International License. 


\title{
Content and uniformity of stereotypes and meta-stereotypes of homeless people in Madrid (Spain)
}

\author{
José Juan Vázquez \\ Dept. Social Psychology \\ Instituto Universitaro de Investigación en Estudios Latinoamericanos (IELAT) \\ Universidad de Alcalá \\ Sonia Panadero \\ Dept. Clincal Psychology \\ Universidad Complutense de Madrid \\ Claudia Zúñiga \\ Dept. Psychology \\ Universidad de Chile
}

\begin{abstract}
This study analyses the content and the uniformity of meta-stereotypes among homelessness people, and the stereotypes that domiciled people have of homeless people. The research took place in Madrid (Spain), based on data provided by a representative sample of homeless people $(n=188)$ and a sample of people at no risk of becoming homeless $(n=180)$. Results show that stereotypes of homeless people and homeless people's meta-stereotypes predominantly have negative or indulgent content, with very little positive content, and have a high degree of uniformity, with hardly any differences in terms of basic socio-demographic variables. The meta-stereotypes of homeless people are more uniform, and are more negative and less indulgent than the stereotypes that domiciled people have established regarding homeless people.
\end{abstract}

Key words: stereotypes, meta-stereotypes, homeless, poverty, social exclusion. 


\title{
Content and uniformity of stereotypes and meta-stereotypes of homeless people in Madrid (Spain)
}

\begin{abstract}
Although there are many definitions of the term "stereotype", those definitions generally emphasize the idea that stereotypes tend to attribute general psychological characteristics to human groups. For example, Hilton and Von Hippel (1996) defined stereotypes as beliefs about the characteristics, attributes and behaviour of the members of certain groups. These beliefs, which may be positive or negative (Jones, 1997), arise in a specific cultural context and are largely shared both within groups and between different groups. Vorauer, Main and O'Connell (1998) use the term "metastereotype" to refer to the beliefs that the members of an ingroup have concerning the stereotypes assigned to them by an outgroup. Whether as a result of direct or vicarious exposure to prejudicial behaviour, socialization within the group itself and/or other social learning mechanisms, the members of a stereotyped group may notice and become aware of the cognitive representations that members of other groups have of them (Saiz, Merino \& Quilaqueo, 2009).

It is important to consider two specific aspects in an analysis of stereotypes and metastereotypes (Saiz et al., 2009): content and uniformity. The content refers to the attributes that make up the stereotype or meta-stereotype, which imply a positive or negative evaluation of the group (Gómez, 2002). Furthermore, the uniformity of the stereotype refers to the degree of consensus on the attributes that are assigned to a group, while the uniformity of the meta-stereotype refers to the degree of consensus among the ingroup members about the attributes they are assigned by the outgroup. For an attribute to be stereotypical, this belief must be shared by a significant proportion of the group. For meta-stereotypes, there must be some degree of agreement within the ingroup in terms of the perception of the outgroup as having particular attributes (Finchilescu, 2005). As suggested with regard to stereotypes (Triandis et al., 1982), greater uniformity in meta-stereotypical beliefs may reflect an increased importance of these beliefs in the ingroup and consequently lead to more intense effects in the interaction between groups (Saiz et al., 2009).
\end{abstract}

The scientific literature highlights positive correlations between cognitive variables (e.g. stereotypes, meta-stereotypes, causal attributions...), emotions (e.g. fear, suspicion, distrust...) and behaviours (e.g. avoidance, rejection, discrimination...) (Breckler, 1984; Zanna \& Rempel, 1988). The consequences of cognitions at a behavioural level may be particularly relevant, because stereotypes and meta-stereotypes may be used to justify behaviour towards members of other groups, for example. Furthermore, meta-stereotypes and stereotypes may also act as cognitions which by their nature modulate the processes of integration of individuals belonging to groups experiencing situations of difficulty or social exclusion. As pointed out by Greenwald and Banaji (1995), social behaviour towards certain groups, and especially those that are stigmatized and suffering from social exclusion, is strongly mediated by stereotypes, which are closely linked to unintentional discriminatory behaviour. This factor has also been emphasised by Kurzban and Leary (2001), who note that human beings have a strong tendency to avoid people in a situation of social exclusion. Shelton and Richeson (2005) have highlighted the tendency for individuals to avoid contact with members of other groups when they believe that these groups do not wish to come into contact with them, with the attributions as to why the members of the outgroup do not want to initiate these contacts differing in the two groups. As noted by several authors (Finchilescu, 2005; Vorauer, Main \& O'Connell, 1998; Vázquez, 2016), the ingroup's negative beliefs about how it is perceived by the outgroup can influence how the members of the ingroup perceive the outgroup, and can therefore significantly affect the former's contact with the latter. 
In Spain, 27.3\% of the population is at risk of poverty or exclusion (EUROSTAT, 2014), and homeless people are those suffering from one of the most difficult social situations (Panadero, Guillén \& Vázquez, 2015). Homeless people not only live in extreme poverty, but also suffer from a high degree of family and social disengagement, have serious difficulties reintegrating into society and employment, and experience significant deficiencies in health (Vázquez, Panadero, Martín, \& DíazPescador, 2014; Panadero, Guillén \& Vázquez, 2015). According to the Spanish National Statistics Institute, the homeless population in Spain cared for in centres amounts to 22,938 people (INE, 2012), but various non-governmental organizations estimate that there are more than 30,000 homeless people in Spain (Plujá i Calderon, 2011).

Stereotypes of homeless people mainly have very negative characteristics, which may lead to negative attitudes towards this group, (Hocking \& Lawrence, 2000; Mallet et al., 2003), hindering their processes of integration. However, stereotypes of the homeless may vary depending on the cultural context. There is little information available about the meta-stereotypes of homeless people, although Panadero, Guillén and Vázquez (2015) have highlighted the existence of three types of metastereotypes among homeless people in Spain: a positive meta-stereotype (reflecting a positive image); a negative meta-stereotype (reflecting a negative image); and an indulgent meta-stereotype (reflecting an ambivalent image; i.e. despite presenting negative characteristics, they have a condescending and tolerant perspective, which to some extent considers homeless people as victims of circumstance, affected by the situation in which they find themselves).

As noted by Shelton and Richeson (2005), a negative perspective in the meta-stereotypes used by homeless people can lead to a tendency for those people to avoid contact with the domiciled population, in the belief that the latter have no wish to come into contact with them. The experience of feeling oneself to be negatively stereotyped can affect an individual's social perception and emotional reactions towards the outgroup, and may contribute to the avoidance of contact with its members (Finchilescu, 2005; Vorauer et al., 1998, Vázquez, Panadero, \& Zúñiga, in press) or if this avoidance is impossible, to hostile reactions. Fear and anxiety about how they can expect to be treated thus leads homeless people to avoid contact, which hinders their social inclusion processes. In addition, some negative and uniform meta-stereotypes may influence the image that homeless people have of themselves (Klein and Azzi, 2001) and therefore their ability to change the situation in which they find themselves.

The aims of the study is analyses the content and the uniformity of meta-stereotypes among homelessness people, and the stereotypes that domiciled people have of homeless people.

\section{Method}

The research was conducted based on data provided by individuals belonging to two different groups: a Homeless Group (HG) and a Domiciled Group (DG).

Homeless Group (HG) ( $\mathrm{n}=188)$ : a group consisting of a representative sample of homeless people in Madrid ( $84.0 \%$ men, $16.0 \%$ women), who were all adults (mean age=47.57 years old, SD = 12.172), who had spent the night before the interview in a shelter or other facility for homeless people, on the street or in other places not initially designed for sleeping (abandoned buildings, subways, Metro stations, etc.). $71.8 \%$ were Spaniards and $28.2 \%$ were foreign. The sample size of the HG was determined based on the available data for the total number of homeless people in the city of Madrid. We designed a strategy for random sampling in the street and in all housing resources for homeless people in the city of Madrid (shelters and other supervised accommodation). We selected a specific number of participants in each facility proportionately and randomly, according to its capacity. The 
sample selection in the street was carried out randomly and proportionally, based on the number of homeless people sleeping in the streets of Madrid according to the figures obtained from the most recent count carried out in the city.

Domiciled Group (DG) $(\mathrm{n}=180)$ : this group consisted of a sample of people who had their own home, were not using services designed for the homeless, and were not at risk of becoming homeless. The sample, which was not representative, was collected in Madrid using a strategy of "quota sampling", and matched with the HG sample with regard to sex (83.8\% men, $16.2 \%$ women), age (mean age $=45.36$ years old, $\mathrm{SD}=14.037)$ and nationality ( $76.7 \%$ Spaniards, $23.3 \%$ foreigners).

The information was gathered using an instrument designed as a heteroapplied structured interview, which resolved the problems arising from the participants' difficulties in reading and/or understanding. The instrument designed to gather information on meta-stereotypes (HG) consisted of the initial instruction "I would like to know what you think people in general think about homeless people. I am going to read you some alternatives and I would like to tell me whether you agree or disagree with each one," which was followed by a list of 57 statements with the response alternatives "agree" and "disagree". The members of the DG were asked the question "Now we would like to know what characteristics homeless people generally have. We are going to read you some alternatives and we would like to say whether you agree or disagree with each one". This was followed by the same list of 57 statements presented to the HG, with "agree" and "disagree" response alternatives.

\section{Results}

The percentages of agreement with the various statements concerning homeless people (metastereotypes and stereotypes) among the members of the HG and DG are shown in Table 1:

Table 1. Agreement with various statements about homeless people among the components of the Homeless Group - HG - (Meta-stereotypes) and the Domiciled Group - DG - (Stereotypes)

\begin{tabular}{lccc}
\hline & $\begin{array}{c}\text { HG } \\
\text { (Meta- } \\
\text { stereotype) } \\
\text { \% (n) }\end{array}$ & $\begin{array}{c}\text { DG } \\
\text { (Stereotype) } \\
\text { \% (n) }\end{array}$ & \\
& $95.3 \%(163)$ & $85.7 \%(144)$ & $\chi^{2}$ \\
\hline They are consumers of alcohol & $91.6 \%(153)$ & $97.7 \%(172)$ & $6.435^{* * *}$ \\
They lack economic resources & $89.1 \%(147)$ & $81.9 \%(140)$ & $3.514^{*}$ \\
They live hand to mouth and don't think about the & & & \\
future & $89.0 \%(145)$ & $91.9 \%(159)$ & 0.848 \\
They lack motivation & $88.3 \%(144)$ & $81.8 \%(135)$ & 2.748 \\
They are solitary & $86.5 \%(147)$ & $71.5 \%(118)$ & $11.330^{* * *}$ \\
They are drug users & $85.9 \%(146)$ & $93.3 \%(166)$ & $5.101^{*}$ \\
They are physically and psychologically worn out & $85.3 \%(139)$ & $89.3 \%(158)$ & 1.222 \\
They are rejected by society & $82.7 \%(139)$ & $44.0 \%(70)$ & $53.081^{* * *}$ \\
They are lazy & $82.1 \%(138)$ & $77.6 \%(128)$ & 1.080 \\
They don't wash properly, they're dirty & $81.9 \%(131)$ & $90.5 \%(153)$ & $5.217^{*}$ \\
They have had a difficult past & $79.3 \%(130)$ & $69.9 \%(123)$ & $3.924 *$ \\
They are sick & & &
\end{tabular}


They are distrustful

They are difficult to live with and to deal with

They are unstable, problematic

They are idle

They have low self-esteem

They are lazy (easy-going), irresponsible

They are malnourished

They are bohemians, hustlers

They are mentally ill

They have poor social relationships

They are criminals

They are rebels

They are dangerous

They are unfortunate, they have been unlucky

They are pessimists

They blame others for their situation

They are aggressive

Homeless people can't be trusted

They are defenceless

They are vulnerable, defenceless

They don't have any social skills

They are wasteful

They are useless, they can't contribute anything to society

They are free

They are tough, resistant

They are misunderstood

They have a weak character

They live exclusively on the streets

They deserve pity

They lack moral values

They have no family

They appreciate things more

They take advantage of the system

They are caring

They don't attach any importance to material things

They are victims of the system

They are sociable

They are normal, like everyone else

They are courteous, respectful, polite

\begin{tabular}{|c|c|c|}
\hline $78.9 \%$ (127) & $64.5 \%(111)$ & $8.395 * *$ \\
\hline $78.0 \%$ (124) & $60.8 \%(104)$ & $11.372 * * *$ \\
\hline $77.8 \%$ (126) & $48.5 \%(81)$ & $30.205^{* * *}$ \\
\hline $77.6 \%(128)$ & $37.1 \%(63)$ & $56.086^{* * *}$ \\
\hline $77.6 \%(121)$ & $88.1 \%(148)$ & $6.365 * *$ \\
\hline $76.5 \%(124)$ & $43.8 \%(70)$ & $36.145^{* * *}$ \\
\hline $71.4 \%(120)$ & $93.2 \%(165)$ & $28.490 * * *$ \\
\hline $70.1 \%(110)$ & $28.7 \%(49)$ & $56.191 * * *$ \\
\hline $70.7 \%$ (116) & $54.2 \%(90)$ & $9.592 * *$ \\
\hline $69.8 \%$ (111) & $57.9 \%(95)$ & $4.936^{*}$ \\
\hline $69.6 \%$ (119) & $17.2 \%(29)$ & $95.055^{* * *}$ \\
\hline $67.5 \%(112)$ & $39.5 \%(66)$ & $26.136^{* * *}$ \\
\hline $66.3 \%(112)$ & $14.1 \%(23)$ & $93.566^{* * *}$ \\
\hline $66.3 \%(110)$ & $75.7 \%(131)$ & $3.687 *$ \\
\hline $65.8 \%(100)$ & $80.0 \%(132)$ & $8.141 * *$ \\
\hline $64.6 \%$ (104) & $62.2 \%(102)$ & 0.202 \\
\hline $64.3 \%(101)$ & $26.5 \%(43)$ & $45.974 * * *$ \\
\hline $64.2 \%(106)$ & $23.9 \%(38)$ & $53.374 * * *$ \\
\hline $64.0 \%(105)$ & $82.3 \%(144)$ & $14.478 * * *$ \\
\hline $63.7 \%(100)$ & $85.1 \%(143)$ & $19.747 * * *$ \\
\hline $63.5 \%$ (94) & $38.2 \%(66)$ & $20.525^{* * *}$ \\
\hline $63.3 \%(105)$ & $20.3 \%(35)$ & $64.085^{* * *}$ \\
\hline $60.2 \%$ (97) & $10.1 \%(17)$ & $91.852 * * *$ \\
\hline $58.3 \%(88)$ & $30.1 \%(52)$ & $26.167 * * *$ \\
\hline $58.1 \%$ (93) & $42.0 \%(68)$ & $8.398 * *$ \\
\hline $57.7 \%(90)$ & $79.3 \%(134)$ & $17.666^{* * *}$ \\
\hline $56.9 \%(91)$ & $54.5 \%(91)$ & 0.188 \\
\hline $56.8 \%(92)$ & $45.8 \%(77)$ & $3.963 *$ \\
\hline $56.6 \%(90)$ & $69.9 \%(114)$ & $6.165 * *$ \\
\hline $56.4 \%(88)$ & $20.9 \%(34)$ & $42.657 * * *$ \\
\hline $53.8 \%(91)$ & $40.3 \%(71)$ & $6.313^{*}$ \\
\hline $53.1 \%(85)$ & $38.6 \%(66)$ & $7.033^{* *}$ \\
\hline $52.8 \%(86)$ & $9.9 \%(17)$ & $71.740 * * *$ \\
\hline $48.8 \%(81)$ & $50.0 \%(78)$ & 0.047 \\
\hline $48.4 \%(76)$ & $31.8 \%(54)$ & $9.439 * *$ \\
\hline $48.4 \%$ (74) & $60.4 \%(102)$ & $4.657^{*}$ \\
\hline $43.2 \%(67)$ & $43.8 \%(70)$ & 0.009 \\
\hline $41.0 \%(68)$ & $70.8 \%$ (119) & $30.232 * * *$ \\
\hline $40.9 \%(65)$ & $43.6 \%(68)$ & 0.237 \\
\hline
\end{tabular}




\begin{tabular}{lllc}
\hline They are trusting & $36.4 \%(56)$ & $20.5 \%(33)$ & $9.775^{* * *}$ \\
They are optimists & $34.5 \%(51)$ & $10.6 \%(18)$ & $26.536^{* * *}$ \\
They are enterprising, fighters & $32.7 \%(54)$ & $12.7 \%(21)$ & $18.791^{* * *}$ \\
They are hard-working & $24.1 \%(39)$ & $33.8 \%(53)$ & $3.642^{*}$ \\
They are clean & $23.5 \%(38)$ & $13.5 \%(23)$ & $5.451^{*}$ \\
They are happy & $18.1 \%(29)$ & $6.0 \%(10)$ & $11.591 * * *$ \\
\hline
\end{tabular}

$* \mathrm{p} \leq .05 ; * * \mathrm{p} \leq .01 ; * * * \mathrm{p} \leq .001$

Table 1 shows that of the 57 statements mentioned, the members of the HG said they agreed with 47 meta-stereotypes, while the members of the DG they agreed with 27 stereotypes. Over $75 \%$ of the members of the HG and DG said they agreed with a series of stereotypes or meta-stereotypes that were indulgent (lacking motivation, lonely, low self-esteem, physically and psychologically worn out, with a difficult past, socially rejected, lacking financial resources, living hand to mouth and not thinking about the future) and negative (drinkers, don't wash properly, they're dirty). Furthermore, over $75 \%$ of the members HG concurred with other meta-stereotypes that were negative (drug users, lazy, unstable, problematic, lazy, irresponsible, difficult to live with) and indulgent (ill, distrustful), and more than $75 \%$ of the members of the DG said they agreed with other indulgent stereotypes (malnourished, unfortunate, unlucky, pessimistic, helpless, vulnerable, misunderstood). Conversely, a low percentage of the interviewees agreed with positive stereotypes or meta-stereotypes.

Table 1 also shows that there are statistically significant differences in the percentage of agreement with meta-stereotypes (HG) and stereotypes (DG) in 48 of the 57 statements, so that the members of the DG presented higher percentages of agreement with nine statements (indulgent stereotypes), while the interviewees in the HG showed higher percentages of agreement with 37 statements (positive and negative meta-stereotypes).

The differences between the interviewees according to three basic demographic variables for which the two groups were matched (sex, age and nationality) were analysed in order to study the uniformity of stereotypes (DG) and meta-stereotypes (HG) in greater depth. No statistically significant differences were found according to the interviewees' gender, and the differences according to age (Table 2) and nationality (Table 3) are relatively small, especially with regard to the meta-stereotypes of the HG. These results show that there is a great deal of uniformity in both the stereotypes among the members of the DG about homeless people and in the meta-stereotypes used by the members of the HG:

Table 2. Differences according to age in the level of agreement with various statements about homeless people among the Homeless Group (HG) (meta-stereotypes) and the Domiciled Group (DG) (Stereotypes)

\begin{tabular}{lccc}
\hline & $\begin{array}{c}\text { Yes } \\
\text { M age }- \text { years- } \\
\text { (SD) }\end{array}$ & $\begin{array}{c}\text { No } \\
\text { M age }- \text { years- } \\
\text { (SD) }\end{array}$ & t \\
\hline $\begin{array}{l}\text { People in general think that homeless people... } \\
\text { (HG - Meta-Stereotypes) }\end{array}$ & & & \\
\hline Are rejected by society & $43.00(13.597)$ & $48.46(11.663)$ & $-2.066^{*}$ \\
Are physically and psychologically worn out & $52.63(7.851)$ & $46.63(12.298)$ & $2.999^{* *}$ \\
Are consumers of alcohol & $50.75(3.615)$ & $47.31(12.151)$ & $2.157^{*}$ \\
\hline In general, homeless people... (DG - Stereotypes) & & & \\
\hline Are rejected by society & $44.25(13.947)$ & $51.79(11.370)$ & $-2.265^{*}$
\end{tabular}


Don't attach any importance to material things

\begin{tabular}{ccc}
$48.59(11.668)$ & $43.24(14.641)$ & $2.560^{*}$ \\
$47.75(13.433)$ & $43.13(14.404)$ & $2.143^{*}$ \\
$47.36(13.199)$ & $41.66(14.644)$ & $2.646^{* *}$ \\
$46.70(13.378)$ & $40.62(15.408)$ & $2.470^{*}$ \\
$47.11(14.680)$ & $42.61(13.623)$ & $2.049^{*}$ \\
$53.00(7.226)$ & $44.61(14.124)$ & $3.293^{* *}$ \\
$50.65(14.908)$ & $43.01(13.458)$ & $2.878^{*}$ \\
$48.74(12.944)$ & $42.43(14.292)$ & $2.897^{* *}$ \\
$39.87(12.874)$ & $48.18(13.811)$ & $-3.889^{* * *}$ \\
$43.13(13.811)$ & $49.20(13.679)$ & $-2.596^{* *}$ \\
$45.83(13.531)$ & $38.08(15.586)$ & $2.580^{*}$ \\
$48.68(10.997)$ & $42.83(14.935)$ & $2.609^{*}$ \\
$49.31(13.038)$ & $40.97(13.617)$ & $4.050^{* * *}$ \\
\hline
\end{tabular}

Are argumentative, problematic

Have a weak character

Are unfortunate, they have been unlucky

Are mentally ill

Are happy

Lack moral values

Are rebels

Are tough, resistant

Are normal, like everyone else

Are vulnerable, defenceless

Homeless people can't be trusted

$31(13.038)$

$40.97(13.617)$

$* \mathrm{p} \leq 0.05 ; * * \mathrm{p} \leq 0.01 ; * * * \mathrm{p} \leq 0.001$

Table 2 shows that among the members of the HG, there are only statistically significant differences in terms of age for three of the 57 suggested statements, with the oldest individuals showing higher percentages of agreement with two negative or indulgent meta-stereotypes, and a lower percentage agreeing that homeless people suffer from social rejection. Meanwhile, there are statistically significant differences in fourteen of the 57 statements offered among the members of the DG. The oldest interviewees presented higher percentages of agreement with ten negative or indulgent stereotypes and one positive stereotype (they are happy), while the younger interviewees showed a higher level of agreement with two positive stereotypes (they are tough, resistant, and they are normal, like everyone else) and that they suffer from social rejection.

Table 3. Differences according to nationality in the level of agreement with various statements about homeless people among the Homeless Group (HG) (Meta-stereotypes) and the Domiciled Group (DG) (Stereotypes)

\begin{tabular}{lccc}
\hline & $\begin{array}{c}\text { Spanish } \\
\text { \% (n) }\end{array}$ & $\begin{array}{c}\text { Foreigners } \\
\text { \% (n) }\end{array}$ & $\chi^{2}$ \\
\hline $\begin{array}{l}\text { People in general think that homeless people... (HG- } \\
\text { Meta-Stereotypes) }\end{array}$ & & & \\
\hline Are free & $63.1 \%(70)$ & $46.2 \%(18)$ & $3.403^{*}$ \\
Are misunderstood & $63.4 \%(71)$ & $42.9 \%(18)$ & $5.281^{* *}$ \\
Are normal, like everyone else & $47.5 \%(57)$ & $25.0 \%(11)$ & $6.715^{* *}$ \\
\hline In general, homeless people... (DG-Stereotypes) & \multicolumn{3}{l}{} \\
\hline Have a weak character & $57.4 \%(66)$ & $37.8(14)$ & $4.293^{*}$ \\
Are unfortunate, they have been unlucky & $81.8 \%(99)$ & $56.8 \%(21)$ & $9.743^{* *}$ \\
Are rebels & $44.0 \%(51)$ & $24.3 \%(9)$ & $4.540^{*}$ \\
Have low self-esteem & $91.5 \%(107)$ & $75.0 \%(27)$ & $6.852^{*}$ \\
\hline
\end{tabular}

$* \mathrm{p} \leq 0.05 ; * * \mathrm{p} \leq 0.01 ; * * * \mathrm{p} \leq 0.001$

As shown in Table 3, depending on the nationality of the respondents, of the 57 statements suggested, statistically significant differences in the percentage of agreement were only observed in three meta-stereotypes (HG) and four stereotypes (DG). Thus, among the members of the HG, the Spaniards agreed to a greater extent with the three positive or indulgent meta-stereotypes, while 
among the members of the DG, the Spaniards agreed to a greater extent with four negative or indulgent stereotypes.

\section{Discussion and conclusions}

The results obtained show that in Madrid (Spain), the stereotypes among the domiciled population of homeless people and the meta-stereotypes used by homeless people mainly have negative content (reflecting a negative image) or indulgent content (reflecting an ambivalent image; i.e. despite presenting negative characteristics they have a condescending and tolerant perspective, which to some extent considers homeless people as victims of circumstance, affected by the situation in which they find themselves), with very few positive contents (reflecting a positive image). The meta-stereotypes have a very high degree of uniformity, with hardly any differences in their content according to basic socio-demographic variables such as sex, age or nationality. Meanwhile, the stereotypes are also remarkably uniform, although variables such as age and to a lesser extent nationality appear to have some influence on their content: domiciled people of Spanish origin and especially older people have negative and indulgent stereotypes of homeless people to a greater extent, and fewer stereotypes with positive content.

There is also a mismatch between the contents of stereotypes and meta-stereotypes, so that the meta-stereotypes of homeless people have more negative and less indulgent content than the stereotypes about this community. Homeless people therefore believe that the domiciled population has a worse image of their group than the image that this population says it has, since the stereotypes that it has of homeless people are characterized to a greater extent by describing an image expressed in a tone that is emotionally negative, but rather condescending, which places homeless people in a situation of disability and dependence. Homeless people appear to believe that domiciled people value them less than they really value them, which may unfortunately have negative consequences in their processes of social inclusion.

Unfavourable and very uniform meta-stereotypes of homeless people may adversely affect the contacts they have with the rest of the population, in terms of both the amount of those contacts and their quality. According to Shelton and Richeson (2005), there may be a tendency among homeless people to avoid contact with those who they believe do not wish to come into contact with them, and if these contacts take place, they may lead to situations of hostility. Fear and anxiety about how they expect to be treated may make homeless people avoid contact, which would hinder their processes of inclusion. Furthermore, people have a strong tendency to avoid people who are socially excluded (Kurzban \& Leary, 2001), and uniform and unfavourable stereotypes (indulgent and negative) of homeless people among domiciled people may have a negative effect on the type of relationship they have with them. According to Greenwald and Banaji (1995), social behaviour towards certain groups, and especially those that are stigmatized and suffering from social exclusion, is strongly mediated by stereotypes, which are closely linked to discriminatory behaviour. The stereotype of homeless people may be used as a justification for negative behaviour towards them. In both groups, the avoidance of contact may lead to different attributions regarding the reasons why the members of the outgroup do not wish to initiate these contacts, reinforcing the previously existing negative stereotypes and metastereotypes.

According to Triandis et al. (1982) and Saiz et al. (2009), the high level of uniformity in metastereotypes reflects a high level of relevance of these beliefs for the ingroup, which could lead to severe effects during interaction with members of the outgroup. Likewise, very uniform unfavourable meta-stereotypes may have a negative influence on the image that homeless people have of themselves (Klein \& Azzi, 2001), which could limit their opportunities to change their situation. Nevertheless, if 
the domiciled peoples' indulgent stereotypes influence the content of homeless peoples' metastereotypes, there could be an improvement in homeless peoples' self-image and this could lead to more frequent and positive contacts between the two groups. Information and awareness-raising of homeless peoples' circumstances and characteristics, and an improvement in the amount and type of contacts between them and domiciled people could lead to a change in the content of stereotypes and meta-stereotypes, with potentially positive benefits for the homeless.

This study is limited to Madrid (Spain). This limitation makes it difficult to generalize the results to other contexts, especially bearing in mind the cultural variations in stereotypes and metastereotypes, which are particularly acute among individuals experiencing social difficulties or exclusion (Vázquez, 2016). It therefore seems important to give in-depth consideration to the characteristics of these cognitive processes in different cultural contexts, since the data obtained may be useful in designing intervention strategies aimed at working on stereotypes and meta-stereotypes of vulnerable groups and those experiencing social exclusion.

\section{Acknowledgments}

This research was supported by the "Dirección General de Investigación Científica y Técnica" of the "Ministerio de Economía y Competitvidad" of Spain, in the "VI Plan Nacional de Investigación Científica Desarrollo e Innovación Tecnológica" (Ref. FEM2012-35053).

\section{References}

Breckler, S.J. (1984) Empirical validation of affect, behavior, and cognition as distinct components of attitudes. Journal of Personality and Social Psychology, 47, 1191-1205. DOI: dx.doi.org/10.1037/0022-3514.47.6.1191

EUROSTAT (2014). People at risk of poverty or social exclusion by age and sex. Retrieved 10/06/15 from EUROSTAT website: http://appsso.eurostat.ec.europa.eu/nui/show.do?dataset=ilc_peps01\&lang=en

Finchilescu, G. (2005). Meta-stereotypes may hinder inter-racial contact. South Africa Journal of Psychology, 35(3), 460-472. DOI: 10.1177/008124630503500305

Gómez, A. (2002). If my group stereotypes others, others stereotype my group... and we know. Concept, research lines and future perspectives of meta-stereotypes. Revista de Psicología Social, 17 (3), 253-282. DOI:10.1174/02134740260372982

Greenwald, A.J. \& Banaji, M. (1995) Implicit social cognitions: Attitudes, self-steem, and stereotypes. Psychological Review, 102, 4-27. DOI: dx.doi.org/10.1037/0033-295X.102.1.4

Hilton, J.L. \& Von Hippel, W. (1996). Stereotypes. Annual Review of Psychology, 47, 237-271. DOI: 10.1146/annurev.psych.47.1.237

Hocking, J.E. \& Lawrence, S. (2000). Changing attitudes toward the homeless: The effects of prosocial communication with the homeless. Journal of Social Distress and the Homeless, 9 (2), 91-110. DOI: 10.1023/A:1009466217604

INE (Instituto Nacional de Estadística) (2012). Encuesta a las Personas sin Hogar. Año 2012. Retrieved 21/05/15 from INE website: http://www.ine.es/jaxi/menu.do?L=0\&type=pcaxis\&path=\%2Ft25\%2Fp454\&file=inebase Jones, J.M. (1997). Prejudice and racism. New York: McGraw-Hill.

Klein, O. \& Azzi, A. (2001). The strategic confirmation of meta-stereotypes: How group members attempt to tailor an out-group's representation of themselves. British Journal of Social Psychology, 40, 279-293. DOI: 10.1348/014466601164759

Kurzban, R. \& Leary, M. (2001). Evolutionary origins of stigmatization: The functions of social exclusion. Psychological Bulletin, 127 (2), 187-208. DOI: 10.1037/0033-2909.127.2.187 
Mallet, S., Edwards, J., Keys, D., Myers, P., \& Rosenthal, D. (2003). Disrupting Stereotypes: Young People, Drug Use and Homelessness. The Key Centre for Women's Health in Society. Melbourne: University of Melbourne.

Panadero, S., Guillén, A.I. \& Vázquez, J.J. (2015). Happiness in the street. Overall happiness among homeless people in Madrid (Spain). American Journal of Orthopsychiatry, 85 (4), 324-330. DOI: dx.doi.org/10.1037/ort0000080.

Plujá i Calderon, M. (2011). Con techo y sin hogar. Efectos de la vivienda precaria en la vida de las personas de Barcelona. Madrid: Caritas Española Editores

Saiz, J.L., Merino M.E., \& Quilaqueo, D. (2009). Meta-estereotipos sobre mapuches. Interdisciplinaria, 26(1), 23-48.

Shelton, N. \& Richeson, J. (2005). Intergroup contact and pluralistic ignorance. Journal of Personality and Social Psychology, 88 (1), 91-107. DOI: 10.1037/0022-3514.88.1.91

Triandis, H.C., Lisansky, J., Setiedi, B., Chang, B., Marin, G., \& Betancourt, H. (1982). Stereotyping among Hispanics and Anglos: The uniformity, intensity, direction, and quality of auto and heterostereotypes. Journal of Cross-cultural Psychology, 13, 409-426. DOI: 10.1177/0022002182013004002

Vázquez, J.J. (2016). The stigma of making a living from garbage. Meta-stereotypes of trash pickers in León (Nicaragua). Scandinavian Journal of Psychology, 57 (2), 122-128 Doi: 10.1111/sjop. 12268

Vázquez, J.J., Panadero, S., Martín, R.M. \& Díaz-Pescador, V. (2015). Access to new information and communication technologies among homeless people in Madrid (Spain). Journal of Community Psychology, 43(3), 338-347. Doi: 10.1002/jcop.21682.

Vázquez, J.J., Panadero, S. \& Zúñiga, C. (in press). Actors, observers, and causal attributions of homelessness: Differences in attribution for the causes of homelessness among domiciled and homeless people in Madrid. American Journal of Orthopsychiatry. DOI: dx.doi.org/10.1037/ort0000130

Vorauer, J.D., Main, K.J., \& O'connell, G.B. (1998). How do individuals expect to be viewed by members of lower status groups? Content and implications of meta-stereotypes. Journal of Personality and Social Psychology, 75, 917-937. DOI: 10.1037//0022-3514.75.4.917

Zanna, M.P. \& Rempel, J.K. (1988). Attitudes: A new look at an old concept. In D. Bar-Tal \& A.W. Kruglanski (Eds.), The social psychology of knowledge (pp. 315-334). Cambridge: Cambridge University Press. 